\title{
Stress distribution on the thorax after the Nuss procedure for pectus excavatum results in different patterns between adult and child patients
}

Tomohisa Nagasao, MD, PhD, ${ }^{a}$ Junpei Miyamoto, MD, ${ }^{a}$ Tamotsu Tamaki, PhD, ${ }^{\mathrm{b}}$ Kazuhiko Ichihara, MD, PhD, ${ }^{\mathrm{c}}$ Hua Jiang, MD, PhD, ${ }^{d}$ Toshihiko Taguchi, MD, PhD, ${ }^{c}$ Ryohei Yozu, MD, PhD, ${ }^{e}$ and Tatsuo Nakajima, MD, PhD

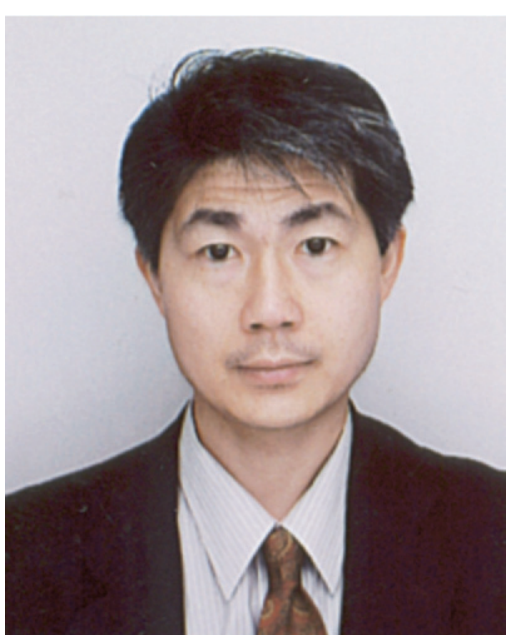

Dr Nagasao

Objective: In the Nuss procedure, in which the deformed thorax is forcibly corrected by insertion of correction bars, considerable stresses occur on the patient's thorax. We performed the present study to elucidate how stress patterns on the thorax after this procedure differ between child and adult patients.

Methods: Eighteen patients with pectus excavatum, constituting a child group ( $\mathrm{n}=$ $10)$ and an adult group $(n=8)$, were included in the study. After a 3-dimensional computer-assisted design model was produced with computed tomographic data from each patient, simulation of the Nuss procedure was performed on the model. Then the stresses occurring on each thorax were calculated using the finite element method. The stresses were compared between the child and adult groups in terms of intensity on each rib and the distribution patterns over the whole thorax.

Results: With all 12 ribs, significantly greater stress occurred in the adult group than stress in the child group. Although the stresses occurring on the thorax demonstrated concentrated patterns in the child group, widely distributed patterns were observed in the adult group.

Conclusions: The stresses that occur on the thorax after the Nuss procedure take different patterns between children and adults in terms of intensity and distribution. The differences should be taken into consideration in managing postoperative pain after the Nuss procedure.

From the Departments of Plastic and Reconstructive Surgery ${ }^{\mathrm{a}}$ and Cardiovascular Surgery, ${ }^{\text {e }}$ School of Medicine, Keio University, Tokyo, Japan; the Nippon Institute of Technology, ${ }^{\text {b }}$ Saitama, Japan; the Department of Orthopedics, ${ }^{\mathrm{c}}$ School of Medicine, Yamaguchi University, Yamaguchi, Japan; and the Department of Plastic and Reconstructive Surgery, ${ }^{\mathrm{d}}$ ChangZheng Hospital, Second Military Medical University, Shanghai, China.

Received for publication May 19, 2007; revisions received July 24, 2007; accepted for publication Aug 16, 2007.

Address for reprints: Tomohisa Nagasao, $\mathrm{MD}, \mathrm{PhD}$, Department of Plastic and Reconstructive Surgery, Keio University Hospital, Shinjuku-Ward Shinanomachi 35 Tokyo, Japan (E-mail: nagasao@ sc.itc.keio. ac.jp).

J Thorac Cardiovasc Surg 2007;134:1502-7

$0022-5223 / \$ 32.00$

Copyright (๑) 2007 by The American Association for Thoracic Surgery

doi:10.1016/j.jtcvs.2007.08.013

$\mathrm{T}$ he Nuss procedure brought innovation to surgical treatment of pectus excavatum. ${ }^{1-5}$ This procedure is advantageous in its reduced invasiveness and technical ease. ${ }^{6-12}$ Because of its feasibility, some institutes use the Nuss procedure as the first-choice treatment option for pectus excavatum. ${ }^{13}$ Although the Nuss procedure is useful, it also has its disadvantages-in particular, postoperative pain. Because the sunken sternum and costal cartilages are forcibly elevated by means of insertion of correction bars, considerable stresses occur on the thorax, often causing a great deal of postoperative pain. It is important to understand the stress occurrence pattern on the thoraces undergoing operation to alleviate the postoperative pain. We conducted the present study to elucidate the intensity and distribution patterns on thoraces after the Nuss procedure.

\section{Materials and Methods \\ Production of Thorax Computer-assisted Design Models}

Collection of computed tomographic data. We collected computed tomographic (CT) data of 18 patients with pectus excavatum. We classified the patients into 2 groups based on their ages. Patients younger than 11 years were included in the child group. Patients older than 20 years were included in the adult group. The average ages of the child group $(\mathrm{n}=10,7$ male and 3 female patients) and of the adult group $(\mathrm{n}=8,6$ male and 2 female 


\section{Abbreviations and Acronyms \\ $\mathrm{CAD}=$ computer-assisted design \\ $\mathrm{CT}=$ computed tomographic \\ $\mathrm{FEM}=$ finite element method}

patients) were $7.4 \pm 2.5$ years and $26.8 \pm 4.6$ years, respectively. For all patients, informed consent was obtained to be included in the present study.

Computer-assisted design model production. Based on the CT data, we produced a computer-assisted design (CAD) model for each of the 18 patients, simulating the patient's thorax. First, we input the CT data into a workstation (Dell Inspiron 6000; Dell Co, Round Rock, Tex). Then, using graphic software (Rhinoceros 4.0; Applicraft Co, Tokyo, Japan), we extracted the data of the thorax part from the original CT data. Furthermore, we edited the data of the thorax by using structural analysis software (ANSYS10.0; ANSYS Co, Chicago, Ill) to produce a CAD model for each patient's thorax (Figure 1). To produce the CAD models, we simulated each of the 12 ribs, the sternum, and each of the 12 vertebrae by using 6,18 , and 36 beam elements, respectively. We simulated each of the costal cartilages by using different numbers of beam elements according to morphologic complexity. For the simulation of each of the first to fifth costal cartilages, 6th to 10th costal cartilages, and 11th to 12 th costal cartilages, 5, 5 to 10 , and 3 beam elements were used, respectively.

\section{Simulation of the Nuss Procedure}

We performed simulation of the Nuss procedure on each thorax CAD model. We conducted the simulation on the assumption that a correction bar was placed at the fourth intercostal space (Figure 2, A). For each thorax, we applied anterior-directed forces on the posterior aspect of the sternum until it reached the same anteriorposterior height as the points on the fifth rib, at which point the correction bar was supported (Figure 2, B). Under these dynamic conditions, we calculated the von Mises stresses that are expected to occur on the thorax by using the finite element method (FEM). We performed the calculation with the structural analysis program available in the software (ANSYS10.0). With the same calculation, we also modeled the corrected shapes of the thoraces (Figure 2, C). We obtained Young's moduli used in the calculation from the CT density of each patient with the methods of Kopperdahl and colleagues. ${ }^{14}$ Kopperdahl and colleagues, after studying 45 vertebral bodies, demonstrated that a linear relationship exists between the quantitative CT density and Young's modulus in the vertebra. The relationship was presented by an equation, $E=-34.7+$ $3230 Q C T$, where E and QCT indicate the Young's modulus (in megapascals) and CT density (in grams per milliliter). Assuming that this equation is applicable for the ribs, sternum, and costal cartilages, we calculated the Young's moduli of these thorax components using the quantitative CT density of the corresponding tissues for each patient. We show the Young's moduli obtained this way in Table 1. We used these Young's moduli for the simulation.
A

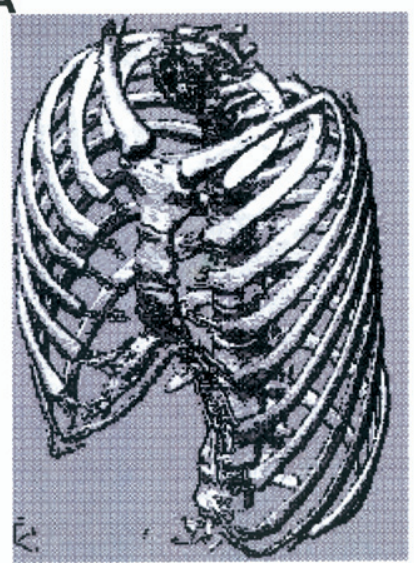

B

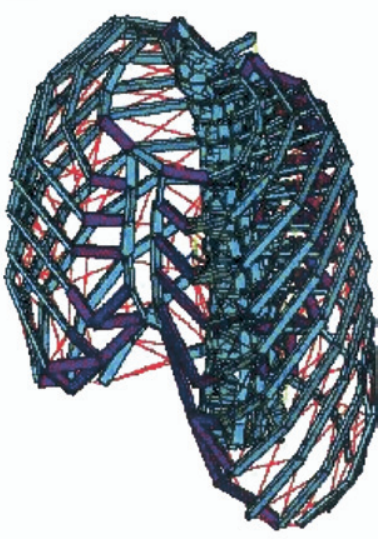

Figure 1. Based on the 3-dimensional computed tomographic data, we produced a computer-assisted design model for each patient. A, Three-dimensional computed tomographic image of a patient. B, Corresponding computer-assisted design model.

\section{Evaluation}

Intensity of the stresses. We compared the intensities of the maximum stresses occurring on each rib between the child and adult groups.

Stress distribution patterns. We compared the patterns in which the stresses were distributed on the thorax between the child and adult groups.
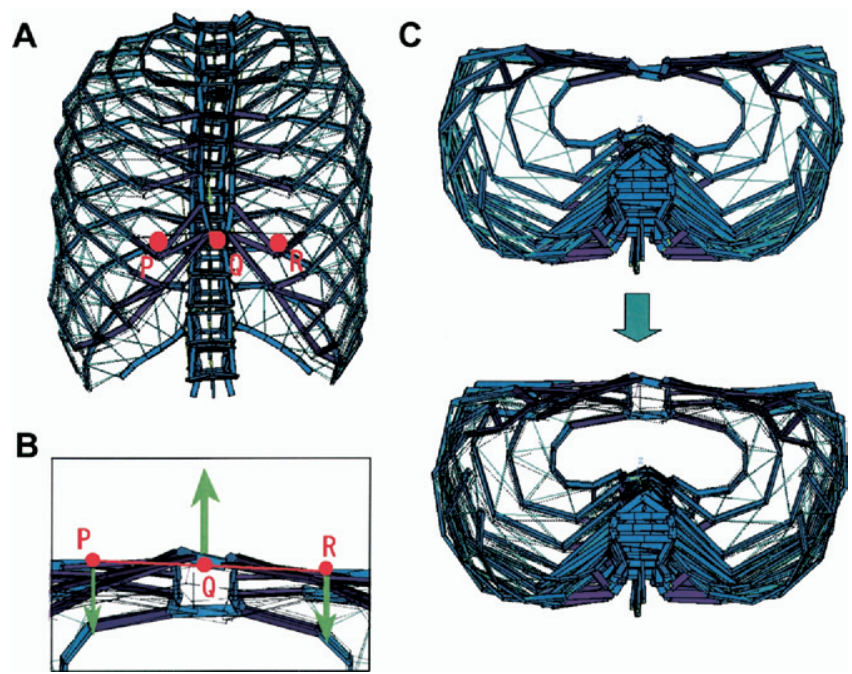

Figure 2. Simulation of the Nuss procedure. A, Three points were marked: at the edges of the bilateral fifth ribs $(P$ and $R)$ and at a point on the posterior aspect of the sternum (Q). B, Assuming that a metal correction bar was inserted at the fourth intercostal space, we applied an anterior-directed force on 0 . We also applied countering forces on $P$ and $R$. We applied these forces until $\mathbf{O}$ reached the segment between $P$ and $R$. Thus the sternum was elevated to a height equivalent with $P$ and R. C, Preoperative (upper) and postoperative shapes (lower) of a simulation model. 


\section{Verification of the Calculations' Validity}

To verify the validity of the simulation, we compared the actual postoperative shapes of the thoraces with the simulation-expected postoperative thorax shapes of the corresponding CAD models. We conducted this verification on 4 patients in whom postoperative CT data were available. For each thorax, we marked points at 6 sites (the center of the sternum, the xiphoid process, and 4 points on the costal margin at which the costal cartilages intersect with the margin; Figure 3). We measured preoperative-postoperative locational changes at the 6 points by using three-dimensional medical imaging software (3D-Doctor; Able Software Co, Lexington, Mass). Thus for the 6 marking points of each thorax, we had 2 data sets of deviation values: the actually measured deviation values and the simulation-expected deviation values. We calculated correlation coefficients between the 2 data sets for each thorax. Thereby we confirmed the validity of the simulation.

\section{Statistical Methods}

For the comparison of the stresses between the child and adult groups, we used a nonparametric examination (Mann-Whitney $U$ test) because the stresses showed skewed distributions. For the examination of the compatibility between actual operative results and results of simulation in the verification experiment, we calculated a correlation coefficient between the 2 data sets. All calculations were performed with SPSS Version 15 for Windows (SPSS, Inc, Chicago, Ill).

\section{Results}

\section{Stress Intensity on Ribs}

On all 12 of the ribs, significantly greater stresses occurred in the adult group than in the child group (Figure 4). The difference was statistically significant for each of the 12 ribs.

\section{Stress Distribution Patterns}

In the child group intensified stresses occurred only on the fifth rib, whereas intensified stresses occurred on the third to the seventh ribs in the adult group (Figures 4 and 5).

\section{Compatibility of the Calculated and Measured Data}

For the 5 cases, the correlation coefficients between the calculated and measured deviation data were $0.995,0.995$, 0.999 , and 0.996 , respectively. The nearness of these correlation coefficients to 1 demonstrates the validity of the simulation.

TABLE 1. Young's modulus for each component material

\begin{tabular}{lccccc}
\hline & \multicolumn{2}{c}{ Child group } & & \multicolumn{2}{c}{ Adult group } \\
\cline { 2 - 3 } \cline { 6 - 7 } & $\begin{array}{c}\text { Median } \\
\left(\mathbf{k g} / \mathbf{m m}^{2}\right)\end{array}$ & $\begin{array}{c}\text { Range } \\
\left(\mathbf{k g} / \mathbf{m m}^{2}\right)\end{array}$ & & $\begin{array}{c}\text { Median } \\
\left(\mathbf{k g} / \mathbf{m m}^{2}\right)\end{array}$ & $\begin{array}{c}\text { Range } \\
\left(\mathbf{k g} / \mathbf{m m}^{2}\right)\end{array}$ \\
\hline Cortical bone & 1520 & $1440-1600$ & & 1750 & $1580-1920$ \\
Cancellous bone & 150 & $140-160$ & & 180 & $160-200$ \\
Costal cartilage & 1.2 & $0.8-1.6$ & & 88 & $62-104$ \\
\hline
\end{tabular}

A

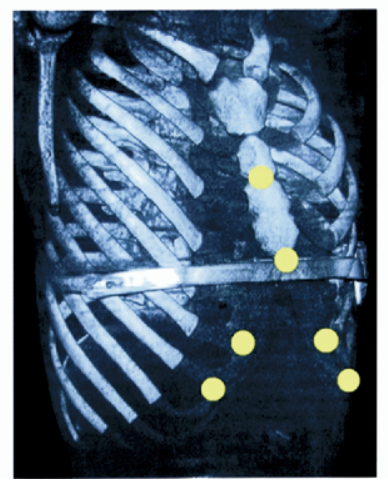

B

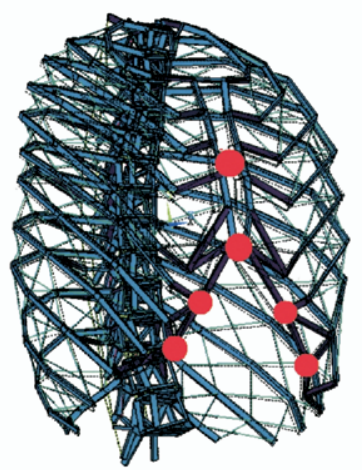

Figure 3. We confirmed validity of the simulation by comparing actual and calculated shapes of the thorax. A, Actual postoperative shape of a patient's thorax. We marked 6 points on the thorax (yellow points) to compare the displacements of the corresponding points (red points in B) of the corresponding computerassisted design model. B, The corresponding computer-assisted design model.

\section{Discussion}

Nuss Procedure and Postoperative Pain

Pectus excavatum is the most common congenital chest wall deformity. ${ }^{15}$ The deformity of the thorax in the pectus excavatum seriously affects the patients' psychologic conditions. Even worse, depressions of the thorax sometimes impair the patients' cardiopulmonary functions. ${ }^{16}$ The Nuss procedure revolutionized treatment of pectus excavatum. ${ }^{1}$ The procedure enabled surgical correction of the deformed thorax with inconspicuous wounds, short operating time, and easy technique. ${ }^{17,18}$

On the other hand, with all the advantages of the Nuss procedure, it is not without problems. Patients who undergo the Nuss procedure often experience intolerable chest pain during certain periods after the operation. In the Nuss procedure malpositioned costal cartilages, ribs, and sternum are forced to realign through the insertion of metal correction bars. Therefore, intensified stresses occur on the thorax, which causes the postoperative pain.

\section{Methods}

In the present study we used the FEM in elucidating the stresses occurring on the patients' thoraces. Because the methodologic reliability of FEM is already validated, it is used for biomechanical analyses of various organs. ${ }^{19-24}$ However, because it is a theoretic method, we believe the validity of the FEM should be confirmed for each experiment. Based on this belief, we conducted verification of the present experiment by comparing the calculated and measured deviation at 6 points of 4 thoraces, with results 


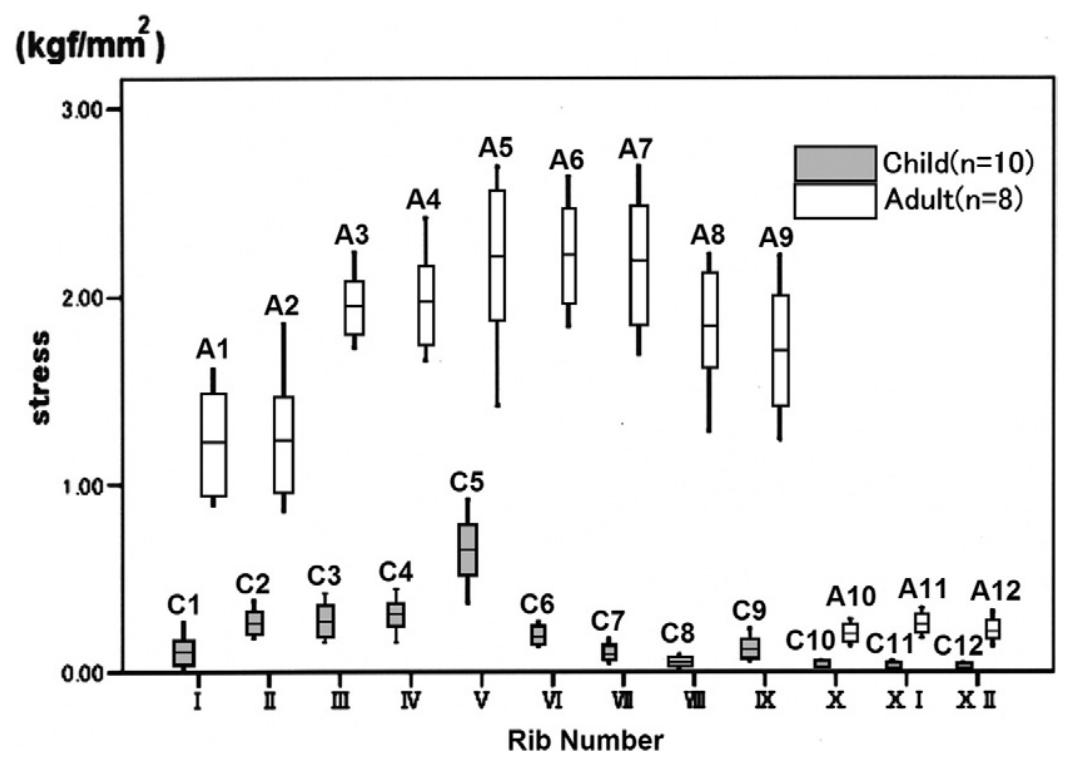

Figure 4. Box plots indicating postoperative stresses on each rib. Each box indicates the range in which $50 \%$ of the data are covered. The bars inside the boxes indicate the averages of the data. The letters on each box indicate the group and number of the rib (eg, A3 indicates the third rib for the adult group).

supporting the methodological correctness of the present experiment.

\section{Findings and Their Clinical Meanings}

Two findings were obtained in the present study. The first finding is that on all 12 ribs, greater stresses occur in adult patients than in child patients. The second finding is that in adult patients intensified stresses occur on plural ribs, whereas intensified stresses only occur on the bar-supporting rib (the fifth rib) in child patients. How do these findings contribute to clinical practices?

In our clinical experience we have perceived that adult patients are more likely to complain of pain than child patients after the Nuss procedure. The average times the patients in the present study took to become ambulatory were $2.3 \pm 1.2$ days for the child group and $5.1 \pm 1.6$ days for the adult group. The difference in tolerance to pain can be supported by the first finding. In adult patients greater stresses occur on the ribs than in those of child patients. Accordingly, greater pain is induced in adult patients than pain in child patients.

We have also perceived that adult patients tend to complain of pain in wider regions of the chest than do child patients. This perception is explained by the second finding. Because stresses as great as those occurring on the barsupporting rib also occur on several neighboring ribs, the adult patients feel pain in a wide range of the thorax. We hypothetically attributed the cause of the second finding to the difference in the flexibility of the costal cartilages between children and adults (Figure 6). Because of the placement of the correction bar at the fourth intercostal space, the sternum is elevated in the anterior direction at this level. Naturally, the sternum is also elevated at other intercostal levels. Because the costal cartilages are attached to the sternum, they are pulled anteriorly as the sternum is elevated and are reshaped. In child patients the costal cartilages are rich in flexibility. Therefore, stresses occurring with the reshaping are absorbed by the costal cartilages. On the other hand, costal cartilages of adult patients are rigid because of age-related ossification. Because of this rigidity, the costal cartilages are less likely to bend according to the elevation of the sternum. Accordingly, the distortion stresses caused
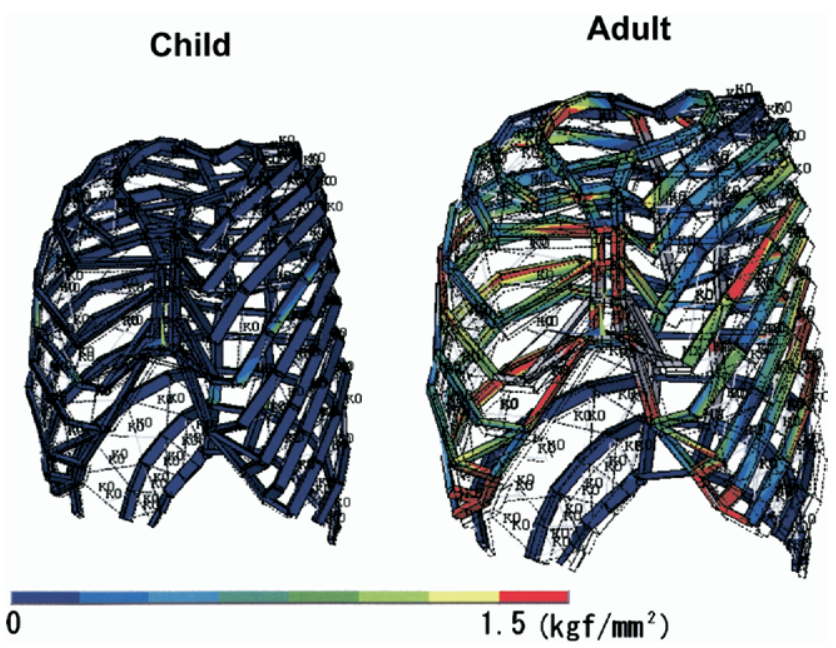

Figure 5. Examples of stress distribution patterns for the child and adult groups. A, In the child patients intensified stresses, although modest compared with those seen in adult patients, occurred only on the bar-supporting rib. B, In the adult patients intensified stresses occurred not only on the bar-supporting rib but also on other neighboring ribs. 


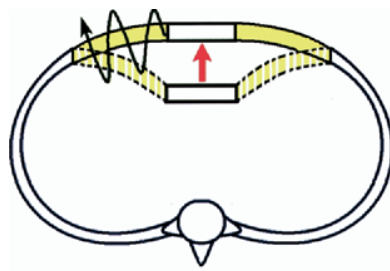

Child

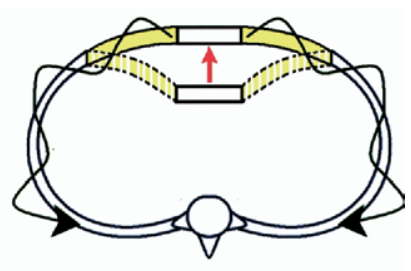

Adult
Figure 6. The authors' hypothetical explanation of the difference of stress occurrence patterns between child and adult patients. A, In child patients stresses caused by the forced elevation of the sternum are absorbed by the costal cartilages because of their flexibility. B, In adult patients the costal cartilages are rigid. Therefore, stresses caused by the elevation of the sternum are transmitted to the ribs without being absorbed by the costal cartilages.

by the sternum's elevation are transmitted to the ribs. Hence in adult patients intensified stresses occur on a wide range of ribs. Because of this wide stress distribution, the adult patients perceive pain in a wide region of the thorax. In performing the Nuss procedure, continuous application of local anesthetic is often conducted through epidural tubes inserted in the patient's back. The second finding suggests that different anesthetic considerations are necessary for child and adult patients. For child patients, it is enough to anesthetize only the bar-supporting rib, whereas for adult patients, it is necessary to extend the anesthetizing areas to include several ribs neighboring the bar-supporting rib.

Besides explaining the pain patterns, the findings of the present study can also be used in predicting the risks of recurrences.

The stresses demonstrated in the results are those occurring on the thoraces immediately after the operation. These stresses are expected to decrease as time passes because of the viscoelastic nature of the human body. However, considering the great difference in the stress intensity between the adult thoraces and child thoraces immediately after the operation, it is reasonable to speculate that the difference will remain even after the stresses decrease in a month-long or year-long period of time. The stresses occurring on the thoraces indicate the forcibility with which their shapes are corrected or the tendency for a thorax to recover its original shape. In other words, high stresses on a thorax indicate the risks of recurrence. Therefore on the condition that stresses on the adult thoraces are greater than those on the child thoraces after a certain period of time, we can assume that risks of recurrence are higher in adult patients than in child patients.

However, the validity of this speculation needs to be proved. With the authors' current analysis technique, we cannot quantitatively predict the stresses occurring on the thoraces in a month-long or year-long period after the operation. As an advanced study, time-related change of the stress on the thoraces should be investigated.

\section{Originality of the Present Research}

Some existing studies have taken a biomechanical approach in their analyses of pectus excavatum. ${ }^{25}$ However, as far as we know, the present study is the first study that quantitatively elucidates stress distribution patterns on the thorax after the Nuss procedure. The authors believe that the findings of the present study help thoracic, cardiovascular, pediatric, and plastic surgeons with their performance of the Nuss procedure.

\section{Conclusions}

We conducted the present study to elucidate differences in stress occurrence patterns on the thorax between child and adult patients with pectus excavatum after the Nuss procedure. On all 12 ribs, greater stresses occur in adult patients than in child patients. Although intensified stresses occur only on the bar-supporting rib in child patients, intensified stresses also occur on other ribs in adult patients. These findings are helpful in managing postoperative pain after the Nuss procedure.

\section{References}

1. Nuss D, Kelly REJ, Croitoru DP, Katz ME. A 10-year review of a minimally invasive technique for the correction of pectus excavatum. J Pediatr Surg. 1998;33:545-52.

2. Hebra A, Swoveland B, Eqbert M, Taqqe EP, Georqeson K, Othersen HBJ, et al. Outcome analysis of minimally invasive repair of pectus excavatum: review of 251 cases. J Pediatr Surg. 2000;35:252-8.

3. Croitoru DP, Kelly REJ, Goretsky MJ, Gustin T, Keever R, Nuss D. The minimally invasive Nuss technique for recurrent or failed pectus excavatum repair in 50 patients. J Pediatr Surg. 2005;40:181-7.

4. Huang PM, Wu ET, Tseng YT, Kuo SW, Lee YC. Modified Nuss operation for pectus excavatum: design for decreasing cardiopulmonary complications. Thorac Cardiovasc Surg. 2006;54:134-7.

5. Schalamon J, Pokall S, Windhaber J, Hoellwarth ME. Minimally invasive correction of pectus excavatum in adult patients. $J$ Thorac Cardiovasc Surg. 2006;132:524-9.

6. Ravitch MM. The operative treatment of pectus excavatum. Ann Surg. 1949;129:429-44.

7. Hawkins JA, Ehrenhaft JL, Doty DB. Repair of pectus excavatum by sternal eversion. Ann Thorac Surg. 1984;38:368-73.

8. Hayashi A, Maruyama Y. Vascularized rib strut technique for repair of pectus excavatum. Ann Thorac Surg. 1992;53:346-8.

9. Bentz ML, Rowe MI, Wiener ES. Improved sternal fixation in the correction of pediatric pectus excavatum. Ann Plast Surg. 1994;32 638-41.

10. Komuro Y, Masuda T, Kobayashi S, Yoza S, Ohmori K. Endoscopic correction of pectus excavatum. Ann Plast Surg. 1999;43:232-8.

11. Nakajima H, Chang H. A new method of reconstruction for pectus excavatum that preserves blood supply and costal cartilage. Plast Reconstr Surg. 1999;103:1661-6.

12. Chang PY, Lai JY, Chen JC, Wang CJ. Long-term changes in bone and cartilage after Ravitch's thoracoplasty: findings from multislice computed tomography with 3-dimensional reconstruction. J Pediatr Surg. 2006;41:1947-50.

13. Petersen C, Leonhardt J, Duderstadt M, Karck M, Ure BM. Minimally invasive repair of pectus excavatum-shifting the paradigm? Eur J Pediatr Surg. 2006;16:75-8

14. Kopperdahl DL, Pearlman JL, Keaveny TM. Biomechanical consequences of an isolated overload on the human vertebral body. J Orthop Res. 2000;18:685-90. 
15. Cartoski MJ, Nuss D, Goretsky MJ, Proud VK, Croitoru DP, Gustin T, et al. Classification of the dysmorphology of pectus excavatum. $J \mathrm{Pe}$ diatr Surg. 2006;41:1573-81.

16. Grillo HC, Wright CD, Dartevelle PG, Wain JC, Murakami S. Tracheal compression caused by straight back syndrome, chest wall deformity, and anterior spinal displacement: techniques for relief. Ann Thorac Surg. 2005;80:2057-62.

17. Boehm RA, Muensterer, Till H. Comparing minimally invasive funnel chest repair versus the conventional technique: an outcome analysis in children. Plast Reconstr Surg. 2004;114:668-75.

18. Molik KA, Engum SA, Rescorla FJ, West KW, Scherer LR, Grosfield JL. Pectus excavatum repair: experience with standard and minimal invasive techniques. J Pediatr Surg. 2001;36:324-8.

19. Nagasao T, Nakajima T, Kimura A, Kaneko T, Jin H, Tamaki T. The dynamic role of "buttress" reconstruction after maxillectomy. Plast Reconstr Surg. 2005;115:1328-1341.

20. Nagasao T, Miyamoto J, Nagasao M, Ogata H, Kaneko T, Tamaki T, et al. The effect of striking angle on the buckling mechanism in blowout fracture. Plast Reconstr Surg. 2006;117:2373-81.
21. Scheltes JS, van Andel CJ, Pistecky PV, Borst C. Coronary anastomotic devices: blood-exposed non-intimal surface and coronary wall stress. J Thorac Cardiovasc Surg. 2003;126:191-9.

22. Grande-Allen KJ, Cochran RP, Reinhall PG, Kunzelman KS Coronary anastomotic devices: blood-exposed non-intimal surface and coronary wall stress. J Thorac Cardiovasc Surg. 2003;126:191-9.

23. Remmler D, Olson L, Duke D, Ekstrom R, Matthews D, Ulrich CG. Presurgical finite element analysis from routine computed tomography studies for craniofacial distraction: II. An engineering prediction model for gradual correction of asymmetric skull deformities. Plast Reconstr Surg. 1998;102:1395-404.

24. Mizunuma M, Yanai A, Tsutsumi S, Yoshida H, Inoue M, Nishida M. Can dog-ear formation be decreased when an S-shaped skin resection is used instead of a spindle skin resection? A three-dimensional analysis of skin surgery techniques using the finite element method. Plast Reconstr Surg. 2000;106:845-51.

25. Weber PG, Huemmer HP, Reingruber B. Forces to be overcome in correction of pectus excavatum. J Thorac Cardiovasc Surg. 2006; 132:1369-73.

\section{JTCVS On-Line Manuscript Submission and Review}

The Journal of Thoracic and Cardiovascular Surgery requires authors and reviewers to submit all new and revised manuscripts and reviews via Editorial Manager. Point your browser to http://jtcvs.editorialmanager.com, log in as author or reviewer (as appropriate), and follow the instructions provided.

To retrieve your username and password, click "Forget your password?" on the Editorial Manager log-in page.

If you have questions or experience problems uploading your manuscript or review, please contact the editorial office:

Telephone: 215-762-1854

E-mail: jtcvs@drexelmed.edu 